\title{
Debate sparked over pharma-funded CME
}

A physician college's decision to keep accepting industry funding for continuing medical education (CME) until it can create a fund to defer costs is reigniting a debate over the ethics of corporate sponsorship.

Earlier in January, the College of Family Physicians of Canada (CFPC) posted a 2013 task force report examining its relationship with the pharmaceutical industry. The report, which the CFPC board approved, acknowledges the industry's "ability to influence the decision-making of family physicians with respect to patient care through its relationship with the CFPC." It highlighted the need for clear guidelines to govern the relationship, particularly around CME courses and conferences.

The report did not, however, recommend prohibiting sponsorships, except for residency and medical student education. Instead, it recommended making sponsorship terms public and separating industry-funded educational and marketing initiatives from those of other sponsors. The task force also advised the CFPC to create a fund by 2016 to support educational activities and to re-examine its principles surrounding industry funding.

To this aim, the CFPC is setting up the "watershed" fund, which will likely be financed primarily by subscriptions from members, says Dr. Jamie Meuser, the college's executive director for professional development and practice support.

"Their subscriptions will pay for the development and dissemination of highquality professional development materials and education programs developed by and for doctors," Meuser says. "Once we have a way of developing truly family-physician-centred education, this will really change the game."

The report's publication sparked media coverage and responses from doctors who are divided about the value and ethics of industry funding for education. Those critical of the practice

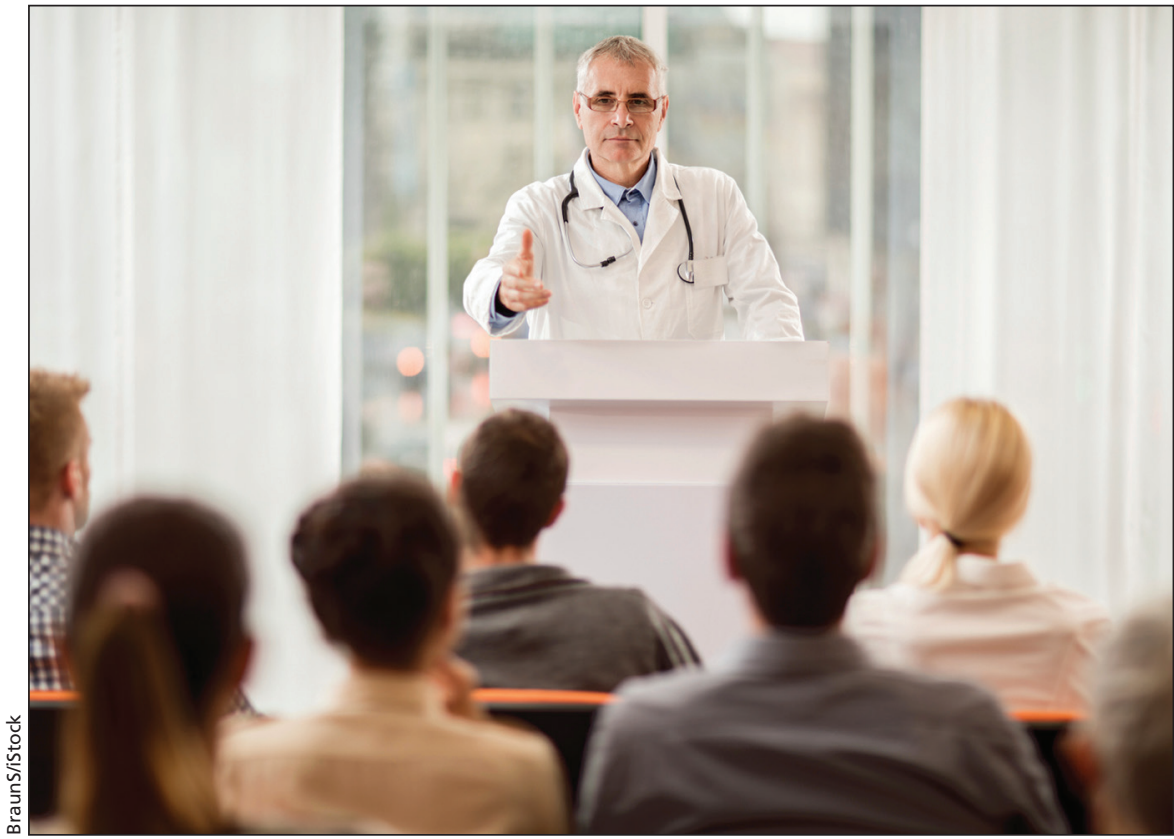

A task force recommends the College of Family Physicians of Canada create a fund to support educational activities.

cite research describing the influence industry funding has on the content of medical education and the speakers chosen for conferences, as well as the often unconscious bias industry marketing instills towards particular drugs or products. That bias undermines a physician's duty to make prescribing decisions based solely on scientific evidence, they say.

"There are a lot of things in the [CFPC taskforce] report that are very weak," says Dr. Joel Lexchin, a health policy professor at Toronto's York University, and one of those who responded negatively to the college's decision.

"There's nothing there about actually looking at whether or not industryfunded [CME] has biases in it," he says. "There's nothing in there about the college reporting how much money it gets from for-profit organizations. There's nothing about looking at whether industry-sponsored CME leads to biases in prescribing."

In addition, doctors "are not poor people" and can afford to finance CME themselves, says Lexchin.
"Doctors are the only ones who get their continuing professional education funded by a profit-making organization that stands to benefit directly from what doctors do, and where the people doctors are serving may have negative outcomes."

Lawyers, for example, who must also undertake continuing professional development, don't have their legal education funded by companies that run for-profit prisons, he says.

Others, including the industry itself, counter with arguments that the sponsored education is evidence-based and offers substantial benefit.

"We believe that the training that we do together adds real value for the health care profession and, most importantly, for the patient," says Russell Williams, president of the industry association Innovative Medicines Canada (former Rx\&D). "It's not only the financial contributions that we have but the expertise within the medical wings of our companies that add great value to that relationship."

But the funding relationship is not 
ideal, according to Dr. Jeff Blackmer, the Canadian Medical Association's vice-president, medical professionalism. "In an ideal situation, you wouldn't have the requirement for industry funding and there wouldn't be any potential for influence." He would like to see a system funded by universities or organizations.

But given the current fiscal situation, it's more realistic to try to balance external funding with physician contri- butions, while enacting regulations to minimize influence, he adds.

Although there are no precise figures on just how much the pharmaceutical industry spends to sponsor continuing medical education in Canada, "most" of the costs are defrayed by the industry, Blackmer says.

At least $50 \%$ of the continuing education programs the CFPC accredits is tied to a sponsorship connection, says
Meuser. Increasingly, however, family doctors are turning to online learning, which is "generally not connected back to pharma," Meuser adds. His hope is that the subscription fund will allow the college to create more such online learning that will be accessible and affordable. - Laura Eggertson, Ottawa, Ont.

CMAJ 2016. DOI:10.1503/cmaj.109-5226 